\title{
Preocupaciones profesionales y académicas de los estudiantes de la carrera de Diseño Gráfico a partir de la capacidad de expresión del meme de Internet en un entorno sociodigital ${ }^{*}$
}

\begin{abstract}
Resumen
La evolución de las tecnologías de la información y la comunicación ha supuesto cambios en la manera en que interactúan y se expresan los individuos, convertidos en su vivir cotidiano en usuarios conectados a través de distintas plataformas de ocio digital. Facebook, al ser la red social más utilizada por los usuarios, se convierte en un espacio donde compartir intereses y experiencias y construir una identidad digital propia. Dentro de los formatos digitales para la difusión de temas o inquietudes sociales cobra gran importancia el meme de Internet, por ello en esta investigación es el objeto de estudio. Los objetivos del trabajo son dos: usar el meme como indicador de transmisión de mensajes en redes sociales e identificar las inquietudes de los estudiantes de diseño gráfico a través de ellos. La metodología se caracteriza por desarrollarse desde un enfoque cualitativo que mediante la observación, el archivo y la extracción de categorías permite localizar las principales problemáticas que ven los estudiantes en relación con su formación académica. Los resultados arrojan siete categorías principales: (1) aspectos personales; (2) aspectos profesionales; (3) materiales; (4) tesis; (5) conceptos de diseño gráfico; (6) institución universitaria y (7) cultura popular. Las mismas se desglosan en categorías específicas y subcategorías entre las que destaca en un nivel más alto la que se refiere al 'estrés' generado en su recorrido académico, así como el "desprestigio profesional" que sufren en el mercado laboral. Como conclusiones igualmente cabe destacar que los memes de Internet sí arrojan información de la personalidad y las preocupaciones del usuario, las cuales cambian a medida que el estudiante avanza de nivel en su carrera.
\end{abstract}

"Autoría compartida al mismo nivel

\section{Nuria Rey Somoza}

Máster en Educación Artística en Instituciones Sociales y Culturales Docente Pontificia Universidad Católica de Ecuador sede Esmeraldas Esmeraldas, Ecuador Correo electrónico: nuria.rey@pucese.edu.ec - orcid.org/0000-0003-1325-5072 Google Scholar

\author{
Melba Cristina Marmolejo \\ Cueva \\ Máster en Tecnologías para la gestión \\ y práctica docente \\ Docente Pontificia Universidad \\ Católica de Ecuador sede Esmeraldas \\ Esmeraldas, Ecuador \\ Correo electrónico: melba. \\ marmolejo@pucese.edu.ec \\ ๑ orcid.org/0000-0001-7718-0685 \\ Google Scholar
}

Recibido: Octubre 25 de 2017 Aprobado: Julio 24 de 2018

\section{Palabras clave:}

Diseño gráfico, educación universitaria, meme de Internet, redes sociales, tecnologías de la información y la comunicación. 


\section{Professional and academic concerns of graphic design undergraduate students, from the ability to express the internet meme in a social-digital environment}

\begin{abstract}
The evolution of information and communication technologies has brought about changes in the way in which individuals interact and express themselves converted into connected users through different digital entertainment platforms in their daily lives. Facebook, being the most used social network, becomes a space where interests and experiences can be shared and an own digital identity can be built. The Internet meme is very important within the digital formats for the dissemination of social issues or concerns, reason why it is the object of study in this research. The objectives of the paper are: to use the meme as an indicator of transmission of messages in social networks, and to identify the concerns of graphic design students through them. The methodology is characterized by developing from a qualitative approach which, through observation, filing and extraction of categories, allows identifying the main problems that students find in relation to their academic training. The results show seven main categories: (1) personal aspects; (2) professional aspects; (3) materials; (4) thesis; (5) concepts of graphic design; (6) university; and (7) popular culture. These are broken down into specific categories and subcategories, among which the one that refers to the "stress" generated in their academic journey stands out in a higher level, as well as the "professional loss of prestige" suffered in the labor market. As conclusions, it is also possible to emphasize that Internet memes can throw information of the personality and the concerns of the users which change as the student progresses to higher levels of his career.
\end{abstract}

Key words:

Graphic design, university education, Internet meme, social networks, Information and Communication Technologies. 


\section{Introducción}

Tanto desde el ámbito sociocultural como desde el educativo se percibe la tendencia hacia el uso de las tecnologías de la información y la comunicación (TIC) como estrategia dentro de los procesos de relaciones sociales y académicas. Las redes sociales han trascendido la función comunicacional en la que emisor y receptor intercambian información dinámicamente para convertirse en modelos que buscan exteriorizar pensamientos e ideologías de cada individuo. En este sentido los procesos de interacción e integración en las redes sociales producirán numerosos formatos gráficos, audiovisuales y textuales que muestren las sensaciones o inquietudes de los usuarios potenciando redes online que se configuren en torno a esos materiales en continuo movimiento.

Dentro de las diversas formas de expresión propias de las nuevas tecnologías, el meme de Internet tiene un rol protagónico a tal punto que ha llamado la atención de investigadores en diferentes disciplinas para desarrollar estudios sobre dicho fenómeno. Se considera meme de Internet, según los estudios seguidores de la teoría memética de Dawkins (1976), a una serie de artefactos culturales que circulan por las redes y comunidades virtuales; por ello se incluyen en esta definición materiales como el spam o los emoticonos. Esta definición - al ser comprendida de manera tan general- integra numerosos productos virtuales denominados como memes, por lo que el meme que se conoce hoy de manera masiva perdería su término de manera particular. Para referirnos a él, y para delimitar el objeto a estudiar en esta investigación, se contempla a este formato como elemento gráfico bidimensional que transita y es compartido por los espacios de la cultura digital sobre todo a través de las redes sociales. A falta de una denominación concreta, en los estudios previos de lo que hoy comúnmente se concibe por meme de Internet, se utiliza el término meme de Internet popular (MIP) para nombrar este material. Siguiendo 
entonces la capacidad expresiva y representativa del MIP como medio de interrelación desde el usuario, este estudio se concentra en los objetivos de considerar este formato como indicador cualitativo de demanda y expresión social y de identificar las preocupaciones de los estudiantes de diseño gráfico a través de este material digital.

La población de la investigación son los estudiantes de la Escuela de Diseño Gráfico de la Pontificia Universidad Católica de Ecuador sede Esmeraldas (PUCE Esmeraldas), y el objeto de análisis serán los memes de Internet que crean y comparten para pronunciarse sobre sus intereses e inquietudes en relación con su formación como futuros profesionales del diseño. Implica, pues, ser consciente como docente o equipo docente de las carencias que perciben los estudiantes sobre su formación y su institución y poder hacer seguimiento de estas problemáticas percibidas para, en el caso de que supongan un grado significativo de inconformidad, abordar distintas posibilidades de solución o respuesta.

A través de la observación, la gestión de material gráfico mediante el archivo y el análisis de las categorías cualitativas, se presentan los resultados y conclusiones del trabajo.

\section{Interacción y cultura remix en las comunidades digitales}

Desde la introducción de las TIC en las distintas dimensiones de la vida cotidiana los procesos de comunicación, interacción e integración social se han visto modificados trasladando la realidad al plano virtual para el desarrollo de estas actividades. Los procesos socioculturales que construyen las diferentes comunidades online han establecido el concepto de cultura digital. Regil (2014) afirma que este término, denominado también cibercultura, consiste en construir la realidad por medios y dispositivos virtuales. De igual manera se explica esta 
concepción como la representación digital del patrimonio físico (European Commission, 2002). Si la cultura digital, según los estudios previos, se configura a partir de la cultura real, se entiende que los espacios sociales se trasladan a plataformas de interacción entre usuarios y que los contenidos y formatos adquieren alta capacidad de circulación desde el carácter gráfico y visual.

La revisión de antecedentes igualmente permite localizar varias características que comparten tanto los espacios como los formatos que conforman esta cultura digital. En primer lugar se puede señalar la necesidad de que las plataformas y contenidos virtuales deben construirse desde un concepto multimedia (García y Gertrudix, 2011). De este modo todos los formatos (gráficos, textuales o audiovisuales) deben convivir en el proceso comunicativo con el fin de enriquecerlo. Por otro lado deben priorizar el carácter transmedia (Scolari, 2014) que permite difundir y expresar un mismo discurso a través de diferentes materiales y dispositivos virtuales. Por último, y atendiendo a las nuevas dinámicas que facilitan las TIC, estos espacios y contenidos digitales se construyen desde la remixación o cultura remix (García y Gertrudix, 2011) que con el objetivo de aumentar el alcance en el mundo virtual se apoya en el fenómeno copyleft al situar al usuario como creador a partir de la reinterpretación y reapropiación de los contenidos digitales que consume.

Estos tres aspectos son fundamentos de las relaciones que posibilitan las TIC a favor de la sociedad del conocimiento, protagonista de la Web 2.0 o Web social y de las eras Web venideras. Esta sociedad del conocimiento representa, según Laraque (2010), poner a disposición la información en los múltiples canales que proporciona la red online con el fin de favorecer una trasformación social mediante las tecnologías. En este sentido tendrán un papel relevante los nativos digitales, generaciones que han crecido en un contexto sociocultural en el que las tecnologías invaden los procesos cotidianos tal como indica Sancho (2008). 


\section{Facebook como espacio de ocio y relación social}

El desarrollo de las TIC hacia la Web social ha transformado todos los aspectos de la cotidianidad. La manera de relacionarse, comunicarse, crear círculos de interés o amistad han pasado a conformarse mediante las dinámicas y lenguajes de la vida virtual en red; esto supone una sociedad en movimiento, más flexible, y a la vez más exigente e impaciente a la hora de recibir e intercambiar informaciones o conocimientos. De la misma manera ha supuesto integrar nuevas prácticas desde el ámbito del ocio, desde la cultura de la imagen, del entretenimiento y la inmediatez (Viñals, Abad y Aguilar, 2014). Como señala Sibilia (2008): estos procesos sociales, frente a la protección de la intimidad, han pasado a conformarse desde la extimidad; es decir la constante exposición del usuario a los demás consumidores de la Web, así como a las empresas tecnológicas desde las que construyen su identidad digital. Por este mismo motivo, la realidad líquida de Bauman (2003) se materializa en una red de redes sociales-digitales a las que se otorgan sensaciones afectivas en favor de una conexión constante con los demás. En estos contextos, se entenderán como procesos de ocio digital a "las oportunidades de ocio que se encuentran ligadas a las posibilidades que ofrece el uso de las tecnologías digitales" (Viñals, Abad y Aguilar, 2014, p. 57).

Destaca el ejercicio de este ocio digital sobre todo entre los jóvenes gracias a la rápida evolución de los sistemas de dispositivos móviles que permiten acumular todas las actividades en diferentes aplicaciones bajo el mismo objeto portátil. Debido a ello, además, se ha agilizado el desarrollo de la capacidad multitarea que ya tiene integrada la generación de nativos digitales.

La red social más destacada y aceptada de las últimas décadas es Facebook, la cual potencia la experiencia comunitaria entre usuarios a partir de las herramientas que ofrece desde la lógica de la Web 2.0. tal como señalan 
Piscitelli, Adaime y Binder (2010). El manejo de estas herramientas permite a los usuarios "construir una especie de narrativa multimedia e instantánea sobre sus propias vidas, presentes y futuras" (Piscitelli et al., 2010, p. 59).

Aranada, Sánchez-Navarro y Tabernero (2009) identifican cuatro acciones que predominan en el uso que se le da a este tipo de plataformas de ocio digital, las cuales son: entretenerse; compartir vídeos y fotografías; actualizarse y conocer lo que ocurre a su alrededor, así como encontrar información de su interés de manera rápida.

La mayoría de las acciones que permite y ofrece este espacio posibilita al usuario pasar de consumidor de materiales digitales a productor de los mismos, adoptando el rol de prosumidor; acrónimo de estos dos conceptos establecido por Toffler (1980). Como prosumidores activos, los usuarios se sienten protagonistas de los espacios virtuales que navegan; convirtiéndose en origen y destino de la información y compartiendo su interés con otros (Piscitelli et al., 2010). Desarrollar las actividades de ocio y difundirlas con otros usuarios es el comienzo de las relaciones digitales que podrán dar lugar a comunidades amplias o concretas comprendidas, según Gallardo, Marqués y Bullen (2015), como espacios de encuentro donde se entablan relaciones personales o profesionales de manera más atractiva. Los estudios de Villena y Molina (2011), por otro lado, indican que los jóvenes consideran que su comportamiento en estas redes es similar a sus dinámicas sociales de la vida real debido a que les otorgan a esas acciones un carácter afectivo, lo que también demuestra la profunda interiorización de los procesos online y digitales por parte de los nativos digitales.

Uno de los ejemplos más claros de construcción de comunidades online en Facebook es la creación o pertenencia a grupos, los cuales se configuran en torno a distintos temas o causas a partir de los materiales y experiencias que 
en ellos se comparten. Por su parte el propio muro de perfil de Facebook, junto con la red de contactos de cada usuario, supone la construcción de una comunidad online. En este caso, primarán los lazos afectivos y de amistad. Además ese fortalecimiento en la conexión entre usuarios permite la creación de otras nuevas, expandiendo el alcance de contenidos en esa red. Cabe destacar, asimismo, el carácter horizontal que pretenden estas comunidades donde la comunicación se establece sin jerarquías. Los procesos, por tanto, se establecen entre iguales y los usuarios en calidad de prosumidores no encontrarán límites en el trato con otros.

De la misma manera es importante indicar de qué forma se manifiesta el usuario dentro de Facebook a nivel individual. Las estrategias comunes se centran en el microblogging, esto es, la continua actualización de entradas o post que publica una persona para entablar comunicaciones con sus contactos o seguidores potenciales. Estos contenidos pueden desarrollarse a partir de vídeos, fotografías o textos tanto de producción propia como exterior. Esto supone la exposición pública del estado de ánimo del usuario, quien expresa su ser en dos dimensiones: el 'yo' interior y el 'yo' exterior. En ambos casos, el individuo construye "estrategias basadas en reforzar los aspectos aceptados socialmente y ocultar los no aceptados" (Piscitelli et al., 2010, p. 63). Por esto, cada usuario configura una identidad digital con la que lograr mayor alcance tanto entre sus contactos como con el público general. Este hecho convive con la idea del avatar, que es la representación gráfica que se asocia a un usuario para su identificación (Saura, 2011). En Facebook este avatar estará conformado por varios elementos: la fotografía de perfil; la de cabecera; la frecuencia y lenguaje empleado en los comentarios; la frecuencia de uso de aplicaciones entre otros.

Piscitelli et al. (2010) señalan que la sociabilidad en Facebook se centra en la subjetividad del individuo-usuario. De esta manera se articula una estrecha 
relación entre consumidores, productores y participantes de los contenidos y del propio espacio de la plataforma.

\section{El meme de Internet como formato gráfico de representación sociocultural}

El término meme, que hoy en día se asocia al formato humorístico que circula por las redes sociales de comunicación, tiene su origen en la teoría memética de Dawkins (1976). En ella se establece el concepto mem en contraposición al gen, siendo este último la unidad elemental biológica que se transmite genéticamente; mientras que el meme es la unidad de transmisión cultural entre iguales y entre generaciones. Los mecanismos de esta transmisión son la imitación, la reproducción de patrones y la reapropiación de elementos culturales que, si no reciben acogida o resultan poco exitosos, no se convertirán en memes y por lo tanto no pasarán a convertirse en un aspecto cultural de una sociedad o comunidad determinada.

Para establecer una diferenciación entre el meme original y el digital se utiliza el término imeme o meme de Internet (Vélez, 2013; Gómez, 2014), que consiste según Davison (2012) en un fragmento viral y cultural que se va transmitiendo de manera online.

Desde esta definición se entienden como memes de Internet no solo a los elementos gráfico-textuales digitales de humor sino a toda una serie de fenómenos masivos de la cultura digital tales como los correos spam, la construcción de figuras mediante caracteres, el Graphic Interchange Format (GIF) o la comunicación a partir de emoticonos como lo explica Gómez (2014). De esta manera el meme de Internet se convierte en un elemento que impregna la mayoría de las acciones y relaciones online, siendo códigos relevantes para los procesos de comunicación presentes y futuros. Contribuye así a cubrir parte de las demandas de interacción entre usuarios, que reclaman cada vez mayores posibilidades para el intercambio y la cultura remix. 
El meme de Internet, según Vélez (2013), supone el "boca a boca" en el plano digital; por tanto, es capaz de difundir cualquier tipo de información con gran alcance. Atendiendo, además, a las explicaciones de Castañeda (2015) se determina que su potencia comunicativa radica en dos aspectos: (i) en el esteticismo del mensaje visual y (ii) en su efectividad en la transmisión de esos mensajes. Por ello el meme de Internet es capaz de comunicar mensajes claros y directos sin que la ironía y el sarcasmo confundan al receptor. Así, se convierte en un material de información y comunicación entre comunidades digitales concretas. Dentro de ellas, y debido a las características mencionadas, es capaz de potenciar la integración o sentimiento de pertenencia en un grupo (Gobato, 2013) y supone la autoafirmación del individuo-usuario dentro de la sociedad virtual a la que pertenece (Pérez, Aguilar y Guillermo, 2014).

El componente humorístico, que predomina en la mayoría de estos formatos, actúa igualmente como elemento de integración y aceptación; ya que, como afirma Vélez (2015), el humor en sí constituye un evento social e incrementa la capacidad de reapropiación del mensaje.

Este formato, desde la perspectiva social, tiene otras connotaciones a destacar puesto que otorga a los usuarios la capacidad de pronunciarse sobre una realidad determinada (Echevarría, 2014). Gutiérrez-Rubí (2014) señala algunos aspectos que convierten a los meme de Internet en formatos de representación de temas sociales al ser artefactos que sirven como medio para potenciar la creatividad social y permitir un fácil acceso y comprensión por usuarios desde cualquier momento y espacio.

Por otro lado, los memes de Internet son reproductores tanto de los estereotipos sociales como de las reivindicaciones dentro de la contrainformación. Según Cortazar (2014) estos se pueden construir desde los clichés sociales debido a que tienen una estrecha relación con el lenguaje del cine, la televisión, los chistes, los refranes populares o las revistas satíricas; de la misma manera que 
pueden transmitir mensajes que se alejan de los mass media, propiciando nuevos significados para aportar otros contenidos y discursos a favor de una sociedad más diversa y multicultural. El autor indica, además, que los memes de Internet son materiales vehiculares de rumores y mitos y que gracias a ello "constituyen un comentario sobre la actualidad" (Cortazar, 2014, p. 192).

De este modo el usuario se pronuncia a través de las comunidades online de las que participa sobre su realidad sociocultural ya sea desde la crítica, la reflexión, el humor entre otros, y mediante formatos audiovisuales, gráficos o textuales con la intención de tener el mayor alcance posible entre sus iguales.

\section{Metodología}

La parte conceptual, que fundamenta los temas y términos en los que se enmarca este estudio, se realizó mediante una revisión y gestión bibliográfica de los estudios previos. Una vez definidos los argumentos, que sustentan el desarrollo del estudio a nivel teórico, se estableció una metodología compuesta por un conjunto de estrategias y técnicas que se construyó sobre los siguientes objetivos generales: utilizar el MIP como indiciador cualitativo transmisor de mensajes y discursos en las redes y comunidades sociales; identificar las preocupaciones e inquietudes de los estudiantes de diseño gráfico en relación con su realidad académica, personal y profesional desde sus manifestaciones en Facebook a partir del MIP.

El estudio se abordó desde un enfoque cualitativo en el que las técnicas que priman son la observación, la clasificación y gestión de los materiales gráficos digitales a considerar y la categorización de las ideas y conceptos más frecuentes de estos materiales. El análisis se realizó de manera descriptiva, exponiendo y desglosando cada categoría y subcategoría que se extrajo de los memes de Internet observados y archivados. 
La población de estudio quedó definida por los estudiantes de la Escuela de Diseño Gráfico de la PUCE Esmeraldas. Para concretar la cantidad de perfiles de estudiantes a revisar se aplicó un muestreo estratificado simple de la siguiente manera: en el primer semestre de 2017 los niveles activos en que se encuentran los estudiantes de la carrera son segundo, quinto, séptimo, octavo y noveno. Cada estrato o nivel, posee datos no homogéneos; es decir que la cantidad de individuos presentaba diferencias notables entre sí, por lo que a criterio del equipo de investigación se seleccionaron 2 estudiantes por cada estrato; la elección de 2 estudiantes de cada uno de los niveles atiende al criterio de ser activos a diario en redes sociales (en concreto, Facebook) para contar con material suficiente y significativo que pudiera aportar al análisis de resultados.

\section{La obtención y gestión de datos se dividió en las siguientes fases de investigación:}

Fase 1. Recolección de datos: la primera acción para obtener datos consistió en la observación directa en la red social Facebook de los estudiantes y finalmente seleccionar los dos más activos de cada nivel de carrera. El criterio de selección obedeció al grado de actividad compuesto por tres escalas: alta, media y baja. Los estudiantes cuyo grado de publicación de MIP correspondían a la escala 'alto', con respecto a otros sujetos del universo, fueron los seleccionados. Se procedió después a una segunda observación de los perfiles de estos estudiantes seleccionados. Esta permitió la descarga y archivo de los MIP detectados que tenían relación con mensajes acerca de opiniones, valoraciones o inquietudes referentes a su formación académica en diseño gráfico. Para la organización de ese archivo de memes de Internet cada sujeto de estudio fue codificado con una nomenclatura definida por la letra ' $M$ ' refiriéndose al término 'meme', seguido del nivel que cursa en la carrera y el apellido del estudiante (por ejemplo: M5QUIÑONEZ). De esta manera se tiene en cuenta el nivel al que pertenece el estudiante para comprobar si existe variedad en las temáticas abordadas en esos memes. 


\begin{tabular}{|c|c|c|c|}
\hline Población & Nivel & Código de muestra & $\begin{array}{c}\text { Cantidad de MIP } \\
\text { (1. } \text {.r }^{\text {er }} \text { semestre 2017) }\end{array}$ \\
\hline Estudiantes de la & $2 .^{\circ}$ & M2LAVAYEN & 20 \\
\hline Escuela de Diseño & & M2HIDALGO & \\
\hline Gráfico PUCE & $5 .^{\circ}$ & M5QUIÑONEZ & 45 \\
\hline \multirow[t]{7}{*}{ Esmeraldas } & & M5GUANO & \\
\hline & $7 .^{\circ}$ & M7BONE & 64 \\
\hline & & M7ZAMBRANO & \\
\hline & $8 .^{\circ}$ & M8REINA & 86 \\
\hline & & M8QUIROZ & \\
\hline & $9 .^{\circ}$ & M9QUINTO & 11 \\
\hline & & M9INTRIAGO & \\
\hline
\end{tabular}

Fase 2. Análisis de datos: de la revisión y categorización de memes de Internet se localizaron varias categorías. El criterio relacional estuvo dado por la percepción post observación de los MIP por parte del equipo investigador, enmarcado en la técnica del brainstorming que facilitó la generación de ideas derivadas en categorías. Por medio de la relación de tópicos de diferentes categorías se pudieron establecer aquellos aspectos que los estudiantes perciben con mayor importancia. Una vez localizadas, todas ellas de manera cualitativa, se procede a aglutinar bajo una denominación común las que pueden englobarse en conceptos más amplios; de manera que finalmente resultan siete categorías generales, desglosadas en subcategorías y categorías específicas dentro de estas últimas. Esta técnica permitió sintetizar, organizar y jerarquizar los datos en las categorías desarrolladas dentro de la fase de recolección para generar un análisis a partir de la comprensión, relación y deducción de las 
ideas presentadas en formato meme. Posteriormente se construyó un mapa de categorías que refleja las preocupaciones de los estudiantes y su relación con sus tópicos cotidianos. Tanto este mapa como la tabla de categorización se muestran detalladamente en los resultados de investigación, acompañados también por algunos de los MIP más ilustrativos de cada categoría.

Por último, cabe destacar algunas consideraciones éticas adoptadas por parte del equipo investigador para no incurrir en ninguna vulneración de la privacidad: (i) poner en conocimiento de los estudiantes el proyecto desarrollado por el equipo investigador que se viene realizando por diferentes vías desde inicios de 2017 gracias a su selección en el concurso de proyectos de investigación de la misma institución universitaria. Esto implica que los materiales compartidos en redes sociales por los estudiantes han podido ser modificados (eliminados de su historial de publicaciones de Facebook), lo que no cambia —en caso de que esto ocurriera- que sean los mismos usuarios con mayor actividad. Aunque Facebook permite borrar publicaciones personales del pasado no permite publicar con fechas pasadas, por lo que la manipulación de información en ese sentido es nula; (ii) queda a criterio de cada docente investigador la relación digital con sus estudiantes, así como las plataformas que utilizan en común. Para este estudio se ha utilizado la Fanpage de Facebook dedicada a la Escuela de Diseño Gráfico, de la que forman parte todos los docentes y estudiantes pertenecientes a la carrera de manera voluntaria y que tiene como objetivo difundir distintas informaciones con respecto a la carrera.

Los perfiles consultados, por tanto, tienen un carácter público y cualquier usuario relacionado puede acceder a la información.

Por su parte el equipo investigador únicamente ha emitido juicios de valor de manera pública sobre los contenidos de los memes de Internet referidos a temas relacionados con la formación académica, el proceso universitario 
o las expectativas laborales como diseñadores de los perfiles digitales de los estudiantes observados.

\section{Resultados y discusión}

Al definir las categorías se sintetizan los tópicos más relevantes para la población de estudio. No obstante, se requiere organizar jerárquicamente los datos de acuerdo con el grado de relevancia reflejado a través del MIP publicado. Para lograrlo se crea un mapa de categorías que visualiza de manera general los intereses, tendencias y preocupaciones durante el proceso de formación y dentro del campo ocupacional alusivo al diseño gráfico.

Lo interesante está en la jerarquía dada en la que se asume como principal preocupación el papel que juega la universidad dentro de su formación profesional y cómo puede incidir en su desempeño laboral.

El análisis de los datos recopilados arrojó siete categorías generales: aspectos personales; aspectos profesionales; materiales; tesis; conceptos de diseño gráfico; institución universitaria y cultura popular. A su vez, cada categoría general tiene categorías específicas que en algunos casos presentan subcategorías. La relación entre ellas se muestra en la tabla 2. 


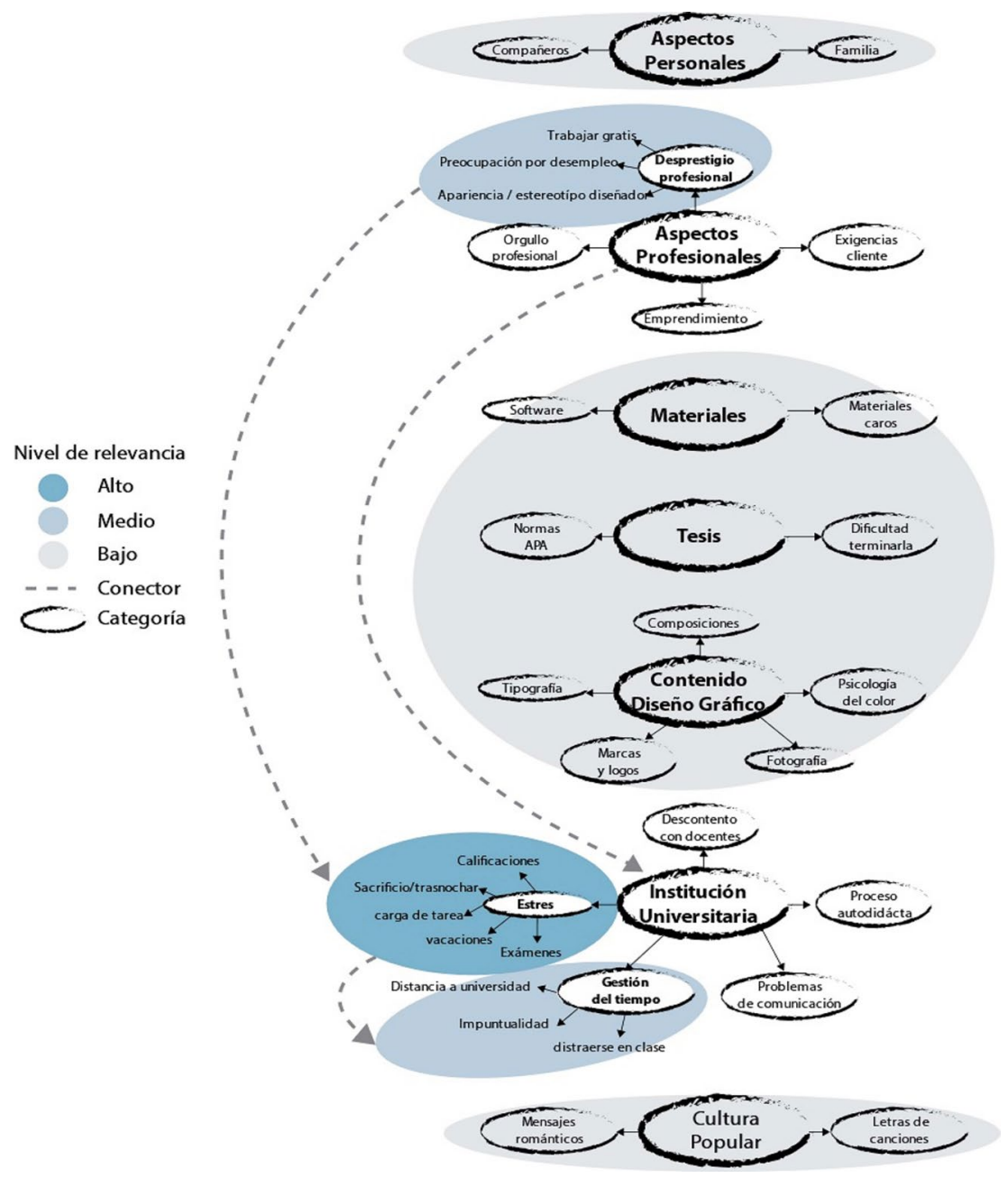

Figura 1. Mapa de categorías. Fuente: elaboración propia por parte de las autoras. 
Rey-Somoza, N. Marmolejo, M.C./ Preocupaciones profesionales y académicas de los estudiantes de la carrera de Diseño Gráfico a partir de la capacidad de expresión del meme de Internet en un entorno sociodigital

Tabla 2. Categorías extraídas de los MIP de los estudiantes de la Escuela de Diseño Gráfico PUCE Esmeraldas (1. er semestre 2017).

\section{\# Categorías generales}

1 Aspectos personales

2 Aspectos profesionales

Materiales

4 Tesis

5 Contenidos diseño gráfico

6 Institución universitaria

\section{Categorías específicas}

1.1. Compañeros

1.2. Familia

2.1. Desprestigio profesional

2.2. Emprendimiento

2.3. Orgullo de su profesión

2.4. Exigencias del cliente

3.1. Software

3.2. Materiales caros

4.1. Normas APA

4.2. Dificultad para terminar

5.1. Tipografía

5.2. Psicología del color

5.3. Composiciones

5.4. Marcas y logos

5.5 Fotografía

6.1. Estrés

Proceso autodidacta

6.3. Descontento con los docentes

6.4. Problemas de comunicación

por parte de la institución

6.5. Gestión del tiempo de estudio

\subsubsection{Impuntualidad \\ 6.5.3. Distraerse en clase}

6.1.1. Calificaciones

6.1.2. Sacrificio/Trasnochar

6.1.3. Carga de tareas

6.1.4. Vacaciones
6.1.5. Exámenes
2.1.1. Trabajar gratis
2.1.2. Preocupación por el desempleo
2.1.3. Apariencia/ Estereotipo del
diseñador gráfico

7 Cultura popular

7.1. Mensajes románticos 7.2. Letras de canciones 
De las siete categorías generales, y como se representa en el mapa de categorías anterior, dos son las que destacan: "aspecto profesional" e "institución universitaria". En el primer caso se evidencia la categoría específica de "desprestigio profesional" como la más relevante; en el segundo caso la categoría específica 'estrés' presenta mayor grado de relevancia, incluso con respecto al "desprestigio profesional" que también se enfatiza. De esta manera, a partir de la relación entre las categorías específicas más destacadas y sus subcategorías correspondientes, resulta la "institución universitaria" como el aspecto que genera mayor estrés; y esta situación se atañe principalmente a la gestión inadecuada del tiempo y a la carga de tarea/exámenes. El segundo aspecto que más preocupación genera a la población de estudio es el "desprestigio laboral", que se evidencia a través de factores como: trabajo gratis, desempleo y estereotipos asociados al diseñador gráfico en el mundo profesional.

\section{cuAndo se te están acumULAdo las taReAS pero tú lo AGARRAS TODO CON CALMA}

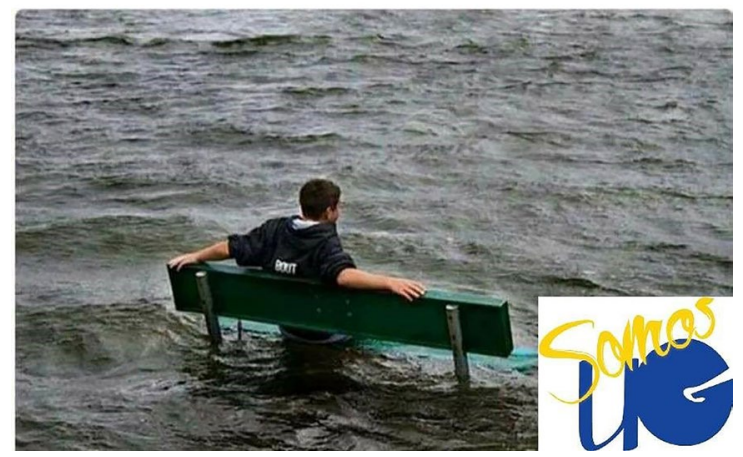

Figura 2. Categoría 6. Institución universitaria; 6.1. Estrés. Diseño: somos UG (comunidad de entretenimiento de la Universidad de Guayaquil). Fuente: perfil personal de Facebook. 

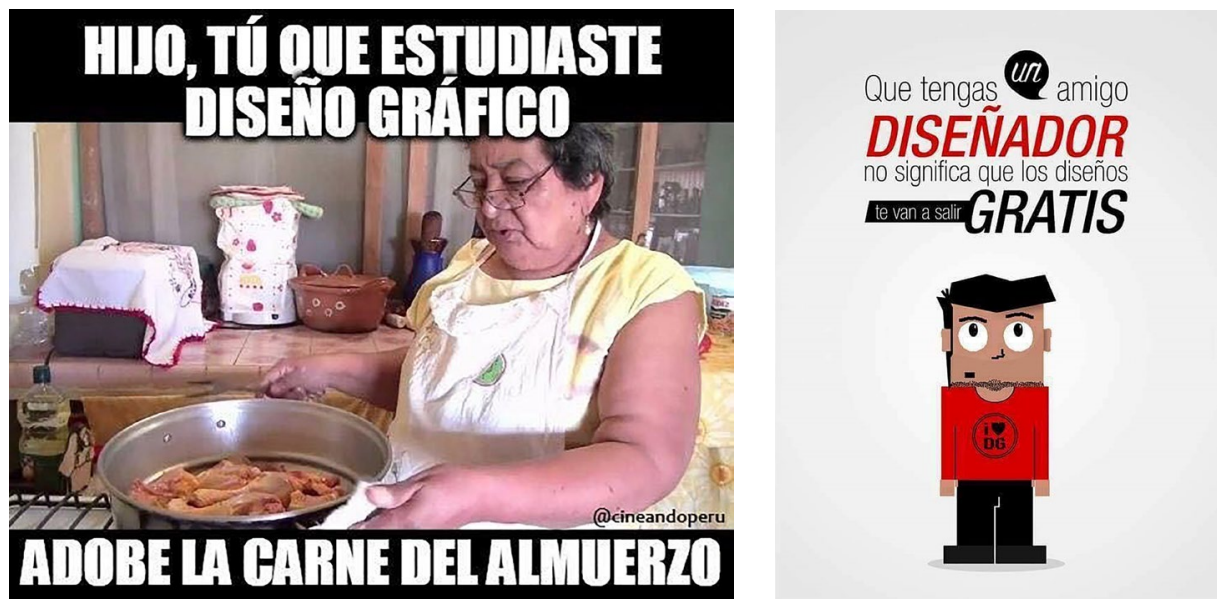

Figuras 3, 4. Categoría 2. Aspectos profesionales; 2.1. Desprestigio profesional. Diseño: @ cineandoperu (Figura 3) y anónimo (Figura 4)

Fuente: perfil personal de Facebook.

El resto de categorías se localizan en media o baja frecuencia, según la escala empleada en los procesos de observación. En grado medio aparecen las categorías: aspectos personales; materiales; tesis y contenidos de diseño gráfico. Desde los "aspectos personales" destacan los materiales MIP que hablan sobre los compañeros de clase y la familia. Centrados en el ámbito académico, el discurso que contienen relacionado con los compañeros es de hermandad y también de énfasis en diferentes clichés o roles de estereotipos sobre los estudiantes que conforman un grupo. 


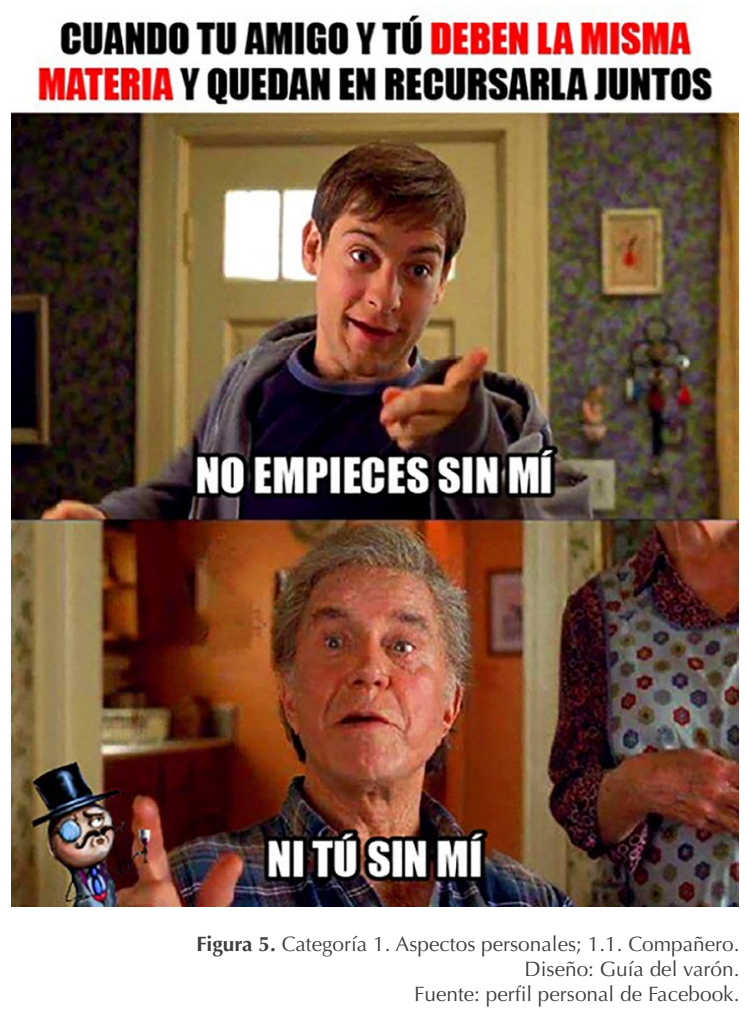

De la categoría 'materiales', destacan como categorías específicas 'software' y "materiales caros". Los que aparecen con mayor frecuencia son los que se refieren desde el humor al uso de distintos programas informáticos para el trabajo en diseño gráfico. 

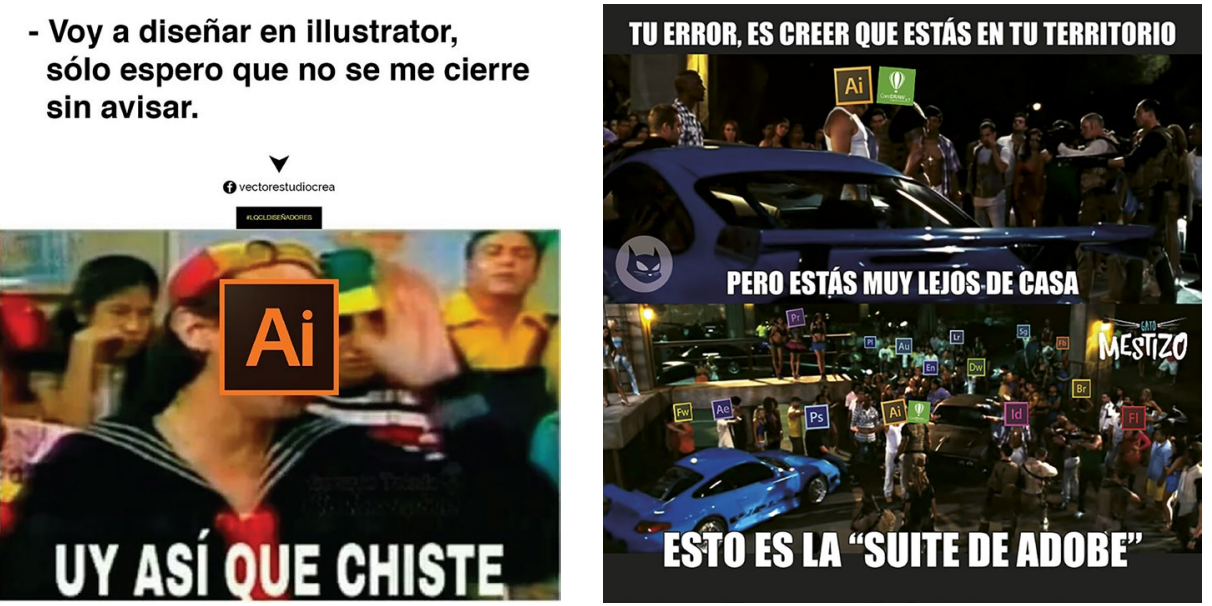

Figuras 6, 7. Categoría 3. Materiales; 3.1. Software. Diseño: vectorestudiocrea (Figura 6) y Gato Mestizo (Figura 7) Fuente: perfil personal de Facebook.

En relación con la categoría 'tesis', destacan en el discurso que arrojan los memes de Internet observados las dificultades que los estudiantes encuentran al realizarla. Por otro lado, sobre los "contenidos de diseño gráfico", se localizan memes de Internet que tratan temas de humor relacionados con la psicología del color, la fotografía, la tipografía, la composición y las marcas existentes. 

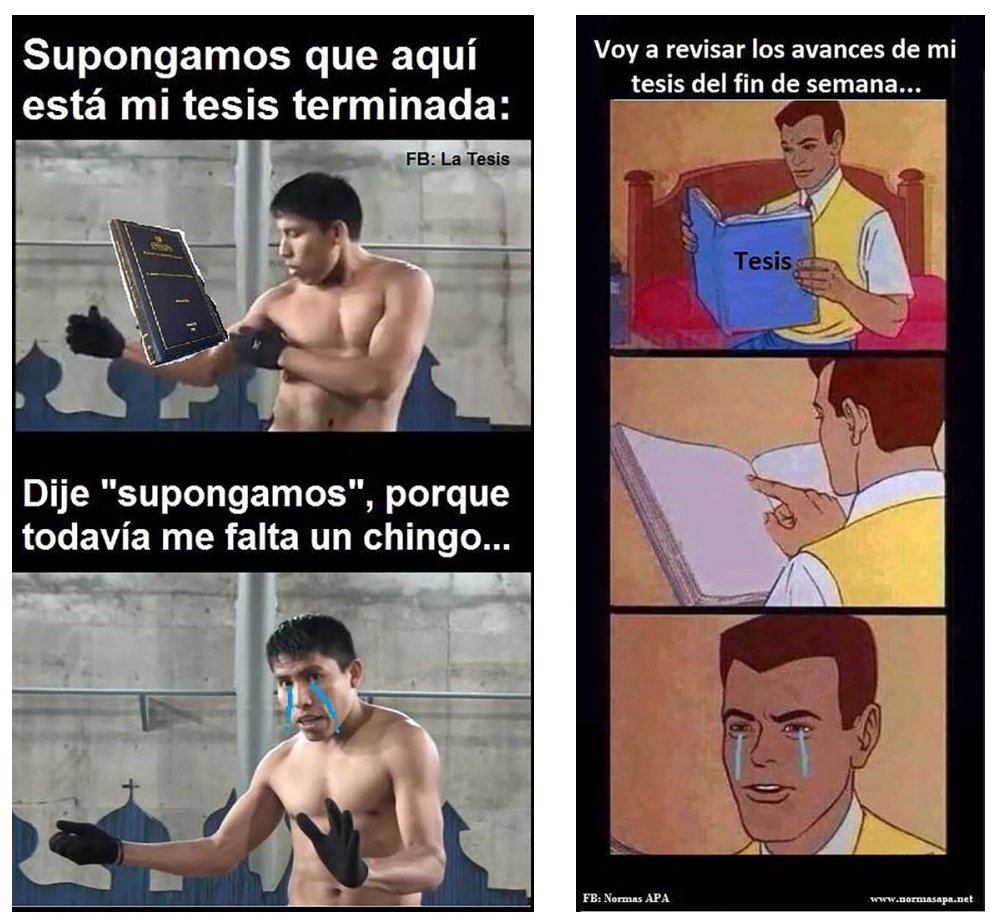

Figuras 8, 9. Categoría 4. Tesis; 4.2. Dificultad para terminar. Diseño: grupo de Facebook "La Tesis" (Figura 8) y grupo de Facebook "Normas APA" (Figura 9). Fuente: perfil personal de Facebook. 

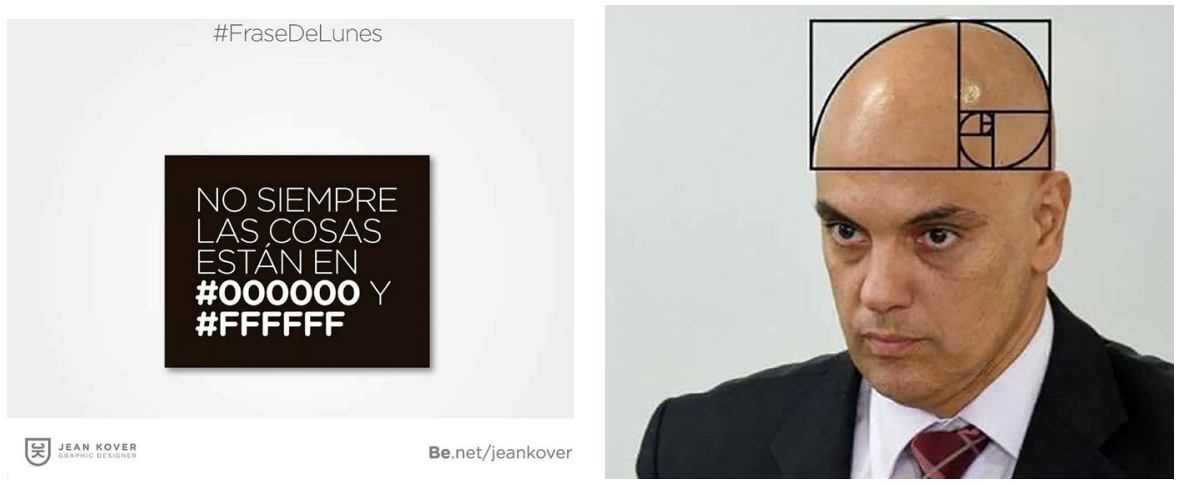

Figuras 10, 11. Categoría 5. Contenidos de diseño gráfico. Diseño: Jean Kover (Figura 10) y anónimo (Figura 11). Fuente: perfil personal de Facebook

La última categoría, que aparece en menor medida en los materiales que comparten los estudiantes en Facebook, se refiere a mensajes que relacionan aspectos del diseño gráfico con la "cultura popular" sobre todo a partir de frases románticas y letras de canciones.

y vectorize el amor

para que nunca se

pixelará...

Figura 12. Categoría 7. Cultura popular; 7.1. Mensajes románticos.

Diseño: Nosotros los diseñadores.

Fuente: perfil personal de Facebook. 
Los referentes teóricos de este estudio presentaban entre otras características esenciales de los materiales digitales online como la capacidad transmedia (Scolari, 2014), así como multimedia y remix (García y Gertrudix, 2011). De entre ellas, la reapropiación que permiten los memes de Internet en favor de discursos concretos (globales o locales) los sitúa no solo como artefactos digitales de humor sino como recurso para la expresión de malestar o demanda en espacios sociales-digitales. Por ello no contribuirán únicamente al esparcimiento en redes sociales (Viñals et al., 2014) sino que afectan y canalizan expresiones que pretenden la aceptación en una comunidad concreta del plano digital o la autoafirmación del usuario que expone su identidad al mundo virtual. De este modo traspasan las acciones principales referidas al ocio en ámbito digital (que, según el estudio de 2009 de Aranada et al., consistían en: entretenerse, compartir imágenes, actualizarse y encontrar información rápidamente) para involucrarse en dinámicas propias del rol prosumidor (productor y consumidor de contenidos). Usuarios que exponen y expresan sus emociones e inquietudes en los medios online donde los memes de Internet, como indica Cortazar (2014), aportan al comentario y debate social sobre los acontecimientos.

Además, estos materiales digitales han desplazado la crítica argumental (Gutiérrez-Rubí, 2014) al contribuir a la inmediatez de reacción y opinión sobre un tema. Por ello si se entiende como indicador cualitativo para detectar sensaciones de los estudiantes con respecto a su formación, como se ha hecho en este estudio, debe entenderse como indicador de punto de partida para localizar las problemáticas existentes y profundizar en ellas por medio de otras estrategias. No quiere decir esto que el meme de Internet sea un artefacto sencillo en su forma y contenido: como se expuso en el desarrollo teórico, el término meme de Internet engloba distintos formatos digitales y online; fragmentos que manifiestan aspectos culturales que, a su vez, formarán parte del concepto macro. Este concepto es definido por Davison (2012) como 
imagen macro y se refiere a cómo de una misma representación visual, que sintetiza una emoción o sensación, pueden derivarse distintos materiales que mantienen esa sensación aun variando otros elementos que la conforman (texto, audio, movimiento entre otros). El MIP, dentro de este universo de expresiones a través de memes digitales, sería la unidad única; con su propia imagen definida a partir de la macro y su propio texto en plano bidimensional. Esto lo convierte en un objeto de estudio más concreto, ya que si se partiera del concepto de imagen macro se abrirían más variables para categorizar los discursos que transmiten y por lo tanto nuevas vías o abordajes para la investigación.

Como formato que puede proporcionar información de situaciones académicas cabe rescatar su potencial uso como recurso tecnológico para el aprendizaje (tecnologías del aprendizaje y el conocimiento o TAC) que han apoyado autores como Sancho (2008) o Moya (2013). Por otro lado, en textos más actuales de Scolari (2018), se apuesta por probar experiencias desde el alfabetismo transmedia en contextos educativos para potenciar una serie de competencias que propician los contenidos digitales online y el rol prosumidor del usuario que los maneja. Estas competencias que adquiere el usuario son varias: habilidad de remezcla o remix de contenidos; de distribución de información; de participación en procesos participativos y colaborativos; nuevos modos de procesamiento e interpretación del contenido entre otros. Destaca el mismo autor, además, que en estos procesos se cruzan aspectos de educación formal e informal al trasladar las relaciones didácticas que se producen en primer lugar en redes sociales hacia el contexto físico del espacio educativo. Esto también ocurre en el presente estudio: las problemáticas que afectan a los estudiantes de diseño gráfico se manifiestan en los entornos sociodigitales que frecuentan y construyen, por lo que sus inquietudes académicas y sus expectativas sobre su profesión son compartidas en el plano digital; antes presentadas a sus círculos o comunidades online que a sus profesores o compañeros de clase. 


\section{Conclusiones}

El avance vertiginoso de la tecnología produce que muchas manifestaciones de la cultura digital se conviertan en obsoletas con rapidez; sin embargo, el interés de los usuarios para gestionar más ágilmente su información dará lugar al surgimiento de otros modelos de interacción y comunicación. En este sentido el meme de Internet demuestra ser un fenómeno comunicacional funcional que no apunta, por el momento, a la obsolescencia ni a la desaparición como formato de la cultura digital.

Aunque el fenómeno del meme de Internet surge como una manifestación de expresión cultural generada por los usuarios en las redes sociales, su función ha trascendido de la mera transmisión viral de un mensaje a todo un sistema complejo de difusión; revelando ideologías y pensamientos de un conglomerado que hoy no pertenece a un contexto específico, sino que más bien se enriquece de la diversidad propuesta en el intercambio dentro de la comunidad global que interactúa constantemente.

De este modo el meme de Internet se ha convertido en un catalizador del pensamiento del usuario que lo difunde, dando la posibilidad de ser utilizado como un indicador que muestra ciertas características del usuario. A través de estos formatos gráficos se han extraído varias categorías que muestran distintos aspectos en relación con los intereses y preocupaciones de los estudiantes de la carrera de diseño gráfico, de forma que se puede afirmar que el meme de Internet es un material válido para percibir tendencias en cuanto a pensamiento y tópicos considerados como relevantes por el sujeto emisor (para este caso, el alumnado).

Las categorías extraídas guardan una relación directa con el nivel formativo de los estudiantes que las publican. Se percibe este hecho concretamente cuando 
se detecta que los estudiantes de los primeros niveles tienen como principal preocupación la carga de tareas; y a medida que avanza el nivel de estudios, sus expresiones se enfocan hacia inquietudes con relación al desprestigio profesional en el mundo laboral del diseñador o el desempleo. Otro dato revelador es que aquellos estudiantes que se encuentran cursando los últimos semestres de la carrera, evidencian su intranquilidad con respecto al desarrollo de la tesis.

Finalmente, una de las maneras en que se pueden considerar los resultados de este estudio es como un reflejo de las carencias de la institución o la actividad docente. Las categorías que tienen una connotación negativa son un punto de partida para mejorar la calidad metodológica hacia los intereses y demandas del estudiante.

\section{Referencias}

Aranada, D., Sánchez-Navarro, J. y Tabernero, C. (2009). Jóvenes y ocio digital. Informe sobre el uso de herramientas digitales por parte de adolescentes en España. Barcelona, España: UOC.

Bauman, Z. (2003). Modernidad líquida. Buenos Aires, Argentina: Fondo de Cultura Económica.

Castañeda, W.M. (2015). Los memes y el diseño: contraste entre mensajes verbalizantes y estetizantes. Revista KEPES, 12 (11), 9-33.

Cortazar, F.J. (2014). Imágenes rumorales, memes y selfies: elementos comunes y significados. Iztapalapa: Revista de Ciencias Sociales y Humanidades, $77,191-214$

Davison, P. (2012). The language of Internet Memes. En M. Mandiberg (Ed.), The Social Media Reader (pp. 129-134). New York, USA: New York University Press. 
Dawkins, R. (1976). The selfish gen. Oxford, England: Oxford University Press.

Echevarría, M.C. (2014). Periodismo digital y redes sociales. Narrativas renovadas: storytelling, storify. En M.C. Echevarría y M.M. Viada (Coord.), Periodismo en la Web. Lenguajes y herramientas de la narrativa digital. Córdoba, Argentina: Editorial Brujas.

European Commission. (2002). The DigiCULT Report. Technological landscapes for tomorrow's cultural economy. Unlocking the value of cultural heritage. Luxemburgo, Luxemburgo: Office for Official Publications of the European Commission.

Gallardo, E., Marqués, L. y Bullen, M. (2015). El estudiante en la educación superior: usos académicos y sociales de la tecnología digital. RUSC. Universities and Knowledge Society Journal, 12 (1), 25-37.

García, F. y Gertrudix, M. (2011). Naturaleza y características de los servicios y contenidos digitales abiertos. CIC. Cuadernos de Información y Comunicación, 16, 125-138.

Gobato, F. (2013). La interacción social en la comunicación contemporánea. Revista de Ciencias Sociales. Segunda época, 5 (23), 49-69.

Gómez, I. (2014). Del meme al imeme, trascendiendo la dimensión lúdica. Entretextos, 5 (15), 1-9.

Gutiérrez-Rubí, A. (2014). Tecnopolítica: el uso y la concepción de las nuevas herramientas tecnológicas para la comunicación, la organización y la acción política colectivas. Recuperado de http://www.gutierrez-rubi.es/wpcontent/uploads/2014/11/Tecnopol\%C3\%ADtica.pdf.

Laraque, C.L. (2010). ¿Sociedad de la información o sociedad del conocimiento? En TIC y Educación. Congreso Iberoamericano de Educación METAS 2021. Buenos Aires, Argentina. 
Moya, M. (2013). De las TICs a las TACs: la importancia de crear contenidos educativos digitales. Didáctica, Innovación y Multimedia. DIM, 27, 1-15.

Pérez, G., Aguilar, A. y Guillermo, M.E. (2014). El meme en Internet. Usos sociales, reinterpretación y significados, a partir de Harlem Shake. Argumentos, 27 (75), 79-100.

Piscitelli, A., Adaime, I. y Binder, I. (2010). El proyecto Facebook y la posuniversidad. Sistemas operativos sociales y entornos abiertos de aprendizaje. Barcelona, España: Editorial Ariel.

Regil, L. (2014). Cultura digital universitaria (tesis de posgrado). Universitat Autónoma de Barcelona, Barcelona, España.

Sancho, J.M. (2008). De TIC a TAC, el difícil tránsito de una vocal. Investigación en la Escuela, 64, 19-30.

Saura, Á. (2011). Exposición itinerante-AVATARES. Revista Iberoamericana de Sistemas, Cibernética e Informática, 8 (2), 55-60.

Scolari, C.A. (2014). Narrativas transmedia: nuevas formas de comunicar en la era digital. En E. Marco y J. Celaya (Dir.), Anuario AC/E de cultura digital (pp. 71-81). Madrid, España: AC/E.

Scolari, C.A. (2018) (Ed.). Adolescentes, medios de comunicación y culturas colaborativas. Aprovechando las competencias transmedia de los jóvenes en el aula. Barcelona, España: Ce.Ge.

Sibilia, P. (2008). La intimidad como espectáculo. Buenos Aires, Argentina: Fondo de Cultura Económica.

Toffler, A. (1980). The Third Wave. New York, USA: Bantam.

Vélez, J.I. (2013). Memética como herramienta científica para el estudio de los memes de Internet (tesis de posgrado). Instituto Tecnológico y de Estudios Superiores de Monterrey, Monterrey, México. 
Vélez, J.I. (2015). Influyendo en el ciberespacio con humor: imemes y otros fenómenos. Versión. Estudios de Comunicación y Política, 35, 130-146.

Villena, J.L. y Molina, E. (2011). ¿Por qué amo las redes sociales? Vida social de jóvenes en red. Revista Interuniversitaria de Formación del Profesorado, 25 (2), 159-173.

Viñals, A., Abad, M. y Aguilar, E. (2014). Jóvenes conectados: una aproximación al ocio digital de los jóvenes españoles. Communication papers: media literacy and gender studies, 3 (4), 52-68.

Como citar: Rey, N. y Marmolejo, M.C. (2019). Preocupaciones profesionales y académicas de los estudiantes de la carrera de Diseño Gráfico a partir de la capacidad de expresión del meme de Internet en un entorno sociodigital. Revista KEPES, 16 (19), 65-94. DOI: 10.17151/kepes.2019.16.19.4 